\title{
Preliminary dielectric and rock magnetic results for a set of prehistoric Amerindian pottery samples from different Venezuelan Islands
}

\author{
V. Costanzo-Alvarez ${ }^{1}$, N. Suárez ${ }^{2}$, M. Aldana ${ }^{1}$, M. C. Hernández ${ }^{2}$, and C. Campos ${ }^{1}$ \\ ${ }^{1}$ Departamento de Ciencias de la Tierra, Universidad Simón Bolívar, Apartado 89000, Caracas 1081-A, Venezuela \\ ${ }^{2}$ Departamento de Física, Universidad Simón Bolívar, Apartado 89000, Caracas 1081-A, Venezuela
}

(Received November 16, 2005; Revised January 10, 2006; Accepted February 3, 2006; Online published November 8, 2006)

\begin{abstract}
Potsherds from 7 Venezuelan islands have been studied using a two-fold magneto/dielectric technique in order to identify clay sources and characterize different stages of pottery craftsmanship. This is the first study of archeological material using this technique. Petrographic analyses appear to agree with the clusters of data identified in scatter plots of initial magnetic susceptibility versus saturation isothermal remanent magnetization (SIRM), and natural remanent magnetization (NRM). Thus, these magnetic parameters appear to be suitable for describing clay source characteristics. Effective magnetic grain sizes, investigated via stability analyses of SIRM and anystheretic remanent magnetization (ARM) upon alternating field (AF) demagnetization, and SIRM acquisition and AF demagnetization crossover plots, seem to be related to different steps of pottery craftsmanship, namely clay preparation, finishing and firing. Thermomagnetic curves might also provide valuable information about original firing conditions. A scatter plot of SIRMs intersections versus maximum current depolarization temperatures and average activation energies, shows a coarse correlation due perhaps to the fact that these rock magnetic and dielectric data are both associated to pore-related features.
\end{abstract}

Key words: Archaeology, pottery, dielectric properties, rock magnetism, provenance studies.

\section{Introduction}

The determination of where a pot was manufactured is of major importance in archaeology, providing evidence of trade and cultural links in past times. However, such sourcing is normally expensive and imprecise because of the complex history of the minerals in a pot. Clays are either primary (residual) or secondary (sedimentary). Primary clays are those found within the same general location as the parent rock from which they originated. Residual clays contain coarse unaltered, angular fragments of the parent rock due to its incomplete alteration and decomposition. Secondary clays appear in contexts far removed from their sources. Transported clays are more common than residual ones and, because of sorting and redeposition, usually have a more homogeneous and finer texture. These clays are then mixed with water and other materials, usually from the immediate area of the clay deposit. After working, they are fired in several possible ways, involving different temperatures and oxidation conditions, duration, etc, that result in physico-chemical changes to the original clay mineralogy. Further changes can then occur during the use of the pots and again after the shards have been abandoned. It is therefore possible to estimate the likely sources of the original materials using chemical analyses such as trace elements, $\mathrm{X}$-ray fluorescence, optical spectroscopy and neutron activation analyses (e.g. Bishop, 1992; Bishop and Blackman, 2002; Neff et al., 2003; Vaz and Cruxent, 1975). These

Copyright (c) The Society of Geomagnetism and Earth, Planetary and Space Sciences (SGEPSS); The Seismological Society of Japan; The Volcanological Society of Japan; The Geodetic Society of Japan; The Japanese Society for Planetary Sciences; TERRAPUB. analyses are usually expensive and prone to the uncertainties introduced by the complex chemical and mineralogical changes that may, or may not, have occurred since the clays were originally excavated though. While such uncertainties may still exist, very cheap (in comparison) analyses can be made that provide information on the nature of the magnetic minerals, including their grain sizes. Previous studies have mostly comprised measurements of the susceptibility and intensity of natural magnetization of shard samples, saturation isothermal remanence and also anystheretic remanent magnetization (ARM) intensities (McDougall et al., 1983). So far, rock magnetic characterizations for archeological purposes, have been applied to obsidian samples from the Eastern Mediterranean region (McDougall et al., 1983), Argentinian and Chilean Patagonia (Vasquez et al., 2001) and central Mexico (Urrutia-Fucugauchi, 1999). In this paper, the new application of the technique of thermally stimulated demagnetization currents (TSDC), is described and compared with more standard magnetic determinations of 19 potsherds (fragments of vessels) with ages spanning from AD 1060 to AD 1530 and collected in 7 Venezuelan islands (Table 1). The main goal is to explore the use of a two-fold magneto/dielectric technique not only for the identification of clay sources, but mostly in the characterization of different steps of pottery craftsmanship, namely how these artifacts were constructed, finished and fired. In the last few years we have led the way in this kind of combined studies in order to define physical markers in fossil-poor sedimentary rocks (Venezuelan Paleogene and Cretaceous formations). Such characterizations have also proved useful in identifying lithological discontinuities and paleoenviron- 
Table 1. Venezuelan archeological pottery samples used in this study.

\begin{tabular}{|c|c|c|c|c|c|}
\hline $\begin{array}{c}\text { Archipielago } \\
\text { or Island }\end{array}$ & Site & $\begin{array}{l}\text { Age } \\
(\mathrm{AD})\end{array}$ & $\begin{array}{l}\text { Depth } \\
(\mathrm{cm})\end{array}$ & $\begin{array}{l}\text { Number of Potsherds } \\
\text { (samples) }\end{array}$ & $\begin{array}{l}\text { Number of } \\
\text { specimens }\end{array}$ \\
\hline \multirow[t]{3}{*}{ Los Roques } & Domusky Norte & $1060 \pm 90$ & 33 & 2 & 21 \\
\hline & Dos Mosquises & $1480 \pm 80$ & $45-47$ & 4 & 31 \\
\hline & Cayo Sal & $1200 \pm 100$ & 35 & 2 & 13 \\
\hline La Blanquilla & Cuevas de la Cabecera & $1130 \pm 120$ & 28 & 5 & 45 \\
\hline \multirow[t]{2}{*}{ Las Aves } & Curricai & $1530 \pm 80$ & 35 & 2 & 11 \\
\hline & Isla del Tesoro & $1530 \pm 80$ & 57 & 2 & 14 \\
\hline La Orchila & Los Mangles & $1370 \pm 80$ & 63 & 2 & 13 \\
\hline
\end{tabular}

Archeological samples (19 samples or potsherds, 149 specimens) were collected from 7 archeological sites or islands. Cultural strata are quite homogeneous and rarely thicker than $60 \mathrm{~cm}$ preventing establishing relative ages between different potsherds in a single location. Radiocarbon ages per site are uncalibrated.

mental changes (e.g. Costanzo-Alvarez et al., 1999, 2000; Suárez et al., 2003).

Archeometric studies in Venezuela are rather incipient. Some of the latest research in this area include archeomagnetic studies (Brandt and Costanzo-Alvarez, 1999), and $\mathrm{X}$-ray fluorescence, instrumental neutron activation analysis and prompt gamma activation analysis (Kasztovszky et al., 2004; Sajo-Bohus et al., 2005). While this work is the first rock magnetic provenance study ever undertaken of Venezuelan pottery samples, it is the first attempt anywhere to characterize archeological material using a combined magneto/dielectric approach.

\section{Samples}

A total of 148 specimens cut from 19 unoriented potsherds (fragments of bowls) have been analyzed. They were collected from 7 archeological sites or islands (Fig. 1, Table 1). These islands are all arid and sandy, and lack clay deposits, sources of freshwater and suitable soils for agriculture. Therefore most of the archeological sites are interpreted as temporary camp sites established by Amerindian groups from Venezuela mainland (M. M. MackowiakAntczak, personal communication). Cultural strata are quite homogeneous and rarely thicker than $60 \mathrm{~cm}$. Therefore archeological stratigraphy renders useless in establishing relative ages between different potsherds collected in a single location. That is also why there is only one uncalibrated radiocarbon age per site (M. M. MackowiakAntczak, personal communication). Visual analysis of the different potsherds reveal colors and textures that vary widely between sites. Colors range from black to red whereas textures go from silty to very coarsely grained.

TSDC analyses were performed in 12 characteristic potsherds from all the sites analyzed, namely Domusky Norte (1), Dos Mosquises (1) and Cayo Sal (1) from Los Roques, Curricai (2) and Isla del Tesoro (1) from Las Aves; Los Mangles (2) from La Orchila and Cuevas de la Cabecera (4) from La Blanquilla.

Rock magnetic characterizations of pottery samples include high temperature susceptibility cycles between room temperature and $700^{\circ} \mathrm{C}$ and the measurement of SIRMs, initial natural remanent magnetizations (NRM) and room temperature magnetic susceptibility. Effective magnetic grain sizes are also investigated via stability analyses of SIRM and ARM upon alternating field (AF) demagnetization curves (Johnson et al., 1975; Cisowski, 1981) and SIRM acquisition and AF demagnetization crossover plots (Symons and Cioppa, 2000). For these experiments it is important to avoid possible magnetic contamination from the outer surface of the vessels, namely pigments from the paintings, slip (i.e. fine coating of clay and water applied over all or most of the surface) or firing heterogeneities. Therefore the homogeneous inner parts of irregular potsherds were carefully selected and cut into several cubic specimens of $1 \times 1 \times 0.3 \mathrm{~cm}$ each $(10 \mathrm{~g}$ weight $)$. These cubes were then embedded into a mixture of magnetically clean 'Plaster of Paris' and water, and left to dry for about 24 hours. Finally $2.5 \mathrm{~cm}$ diameter $\times 2.5$ height cores were drilled from each specimen.

NRM and room temperature magnetic susceptibility measurements were obtained for the 148 specimens, from a total of 19 potsherds analyzed. Room temperature MS measurements were accomplished in a Bartington susceptometer with a dual frequency of the applied field. NRMs were measured in a Molspin minispin rock magnetometer with a sensitivity better than $1 \times 10^{-7} \mathrm{emu} / \mathrm{cc}$ at $24 \mathrm{sec}$. ARM and SIRM experiments were carried out in only two specimens per shard. AF demagnetizations and ARM experiments were performed in a MOLSPIN shielded demagnetizer with a two axis tumbler and a PARM device placed within the demagnetizing coil and which can produce a constant field. IRMs were induced in a ASC IM-10-30 impulse magnetizer with interchangeable coils and capable of generating fields in excess of 28 KGauss.

Curie temperature analyses were carried out in one shard ( $10 \mathrm{~g}$ of solid sample) from each archeological site (i.e. 7 different shards). The equipment used for these measurements was a Bartington MS2 with a MS2W probe that allows continuous susceptibility and temperature readings of a sample heated, up to $700^{\circ} \mathrm{C}$, in a SM2WF furnace.

Thin sections from 9 representative specimens from Cuevas de la Cabecera (3) in La Blanquilla, Dos Mosquises (2) and Cayo Sal (1) in Los Roques, Curricai (1) and Isla del Tesoro (1) in Las Aves and Los Mangles (1) in La Orchila, were examined in transmitted plane (PPL) and crosspolarized light (XPL), at magnifications of $4 \mathrm{X}$ and 10X, us- 

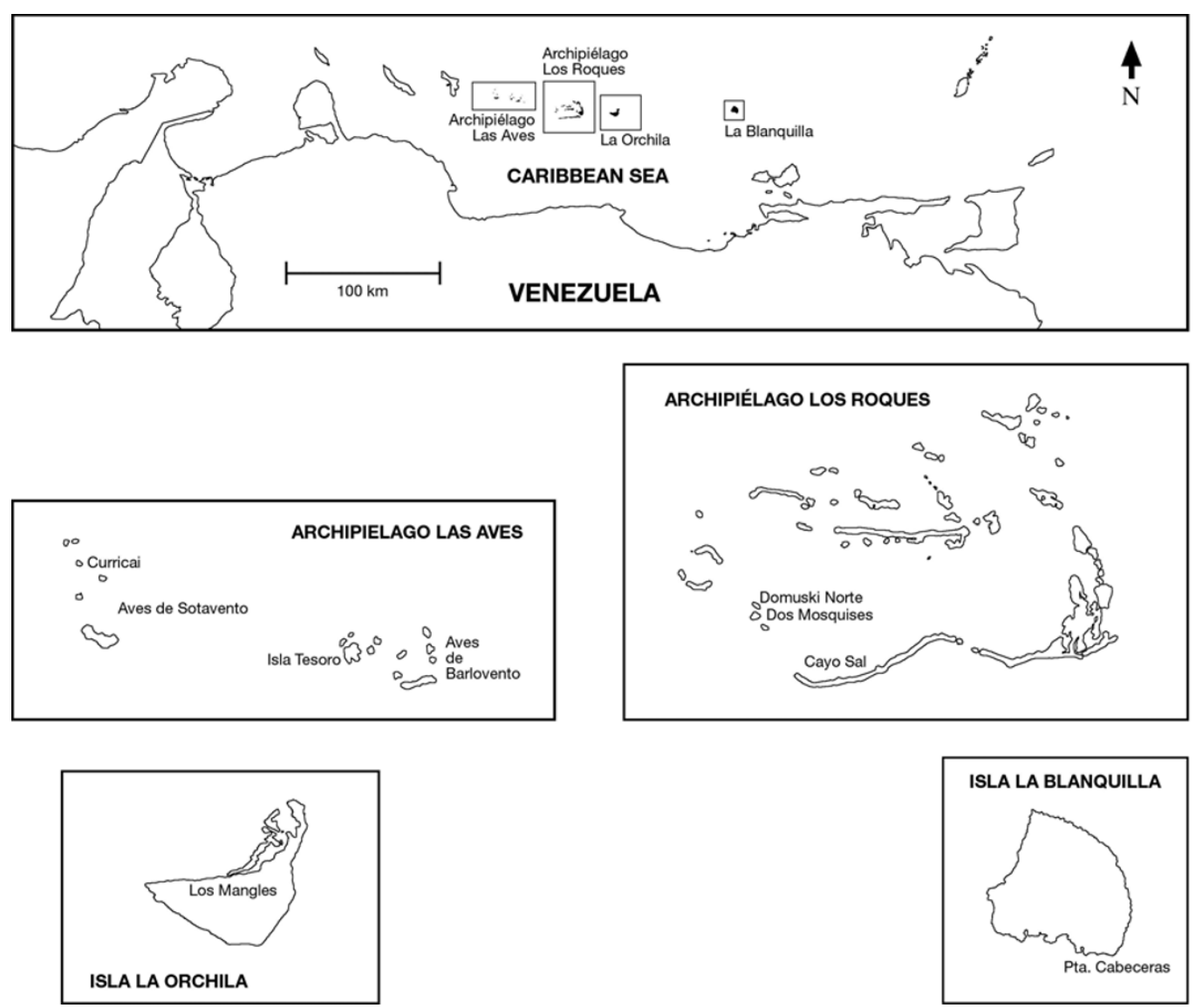

Fig. 1. Sketch map of northern Venezuela showing the islands and archipelagoes with the location of archeological sampling sites.

ing an optical microscope (Zeiss) with a rotating stage, a fully automatic exposure control and a digital camera connected to a microcomputer with image analysis software.

\section{TSDC Experiments and Results}

The technique of thermally stimulated depolarization currents (TSDC) is a well established method in physics. It has been proved effective in investigations of molecular mobility, phase transitions, structure-properties relationships and hydration properties of complex heterogeneous systems. In the last decade, interest in this technique from areas outside its traditional sphere has increased markedly, and the TSDC technique is becoming used even in biotechnology (Suárez et al., 1997), medicine (Suárez et al., 1998) and pharmaceutics (Boutonnet-Fagegaltier et al., 2002).

TSDC technique (Bucci and Fieschi, 1964) studies the variation with temperature of the de-polarization current given by a sample previously polarized at a temperature $T_{p}$, sufficiently high to allow the orientation of the different dipolar species in the presence of an external electric field $E_{p}$. The principle of this technique is based on the strong dependence of the dielectric relaxation time, $\tau$, of the dipolar species on temperature $T$. One of the advantages of this technique is its high sensitivity, leading to the detection of very low dipole or carrier concentrations, and its very low equivalent frequency $\left(\sim 10^{-3} \mathrm{~Hz}\right)$, allowing multicomponent peaks to be resolved accurately. The method allows the isolation of a particular relaxation from its neighbor- ing peaks by carefully choosing the polarization conditions. The disk shaped samples, around $20 \mathrm{~mm}$ diameter and 250 $\mu \mathrm{m}$ thick, are placed between two spring-loaded metallic electrodes. The state of polarization is frozen by quenching the sample rapidly $\left(55^{\circ} \mathrm{C} \mathrm{min}^{-1}\right)$ to liquid nitrogen temperatures. Then the electric field is switched off and the sample temperature is increased at a linear heating rate in order to record, with a Cary Vibrating Reed Electrometer model 401, the depolarization current originated by the disorientation of the dipoles. The sensitivity of our current measuring system is $10^{-17} \mathrm{~A}$ and the signal to noise ratio is better than 500 . The constant heating rate used was $0.07 \mathrm{~K} / \mathrm{s}$ and a typical electric field of $5 \times 10^{5} \mathrm{~V} / \mathrm{m}$ was applied. The current-temperature data acquisition is fully automatic. The depolarization spectrum obtained in a TSDC experiment is composed of current peaks produced by the relaxation process of each dipolar entity. Assuming Arrhenius temperature dependence for the relaxation times of the dipoles, i.e.

$$
\tau(T)=\tau_{0} \exp (E / k T)
$$

where $\tau_{0}$ is the inverse frequency factor and $E$ the reorientation energy characteristic of the process, the expression for the current density of a pure Debye dipole relaxation (Bucci and Fieschi, 1964), can be written as

$$
J_{D}(T)=\frac{P_{0}}{\tau(T)} \exp \left[-\frac{1}{b} \int_{T_{0}}^{T} \frac{d T^{\prime}}{\tau\left(T^{\prime}\right)}\right] .
$$

Frequently, the recorded spectrum is composed by several 
overlapped and non monoenergetic peaks that cannot be described by Eq. (2). This complex spectrum can be modeled as the sum of $N$ Debye processes described by

$$
\begin{aligned}
J_{D}\left(T_{j}\right)= & \sum_{i=1}^{N} \frac{P_{0 i}}{\tau_{i}\left(T_{j}\right)} \exp \left[-\frac{1}{b} \int_{T_{0}}^{T_{j}} \frac{d T^{\prime}}{\tau_{i}\left(T^{\prime}\right)}\right], \\
& (j=1, m),(N \leq m)(2) .
\end{aligned}
$$

The direct signal analysis (DSA) method (Aldana et al., 1994) was applied to analyze the TSDC curves. This method consists in finding the $N$ elementary curves that best fit the experimental spectrum. The result of the adjustment is an energy histogram whose height is the adjusted contribution of each energy bin to the polarization, together with the bestfitted value for the corresponding $\tau_{0 i}$.

Polarization of the pottery samples was carried out by applying an electrical field $\left(5 \times 10^{5} \mathrm{~V} / \mathrm{m}\right)$ at room temper-



Fig. 2. TSDC Spectra of the studied samples. $T_{p}=300 \mathrm{~K}$. All the spectra have been normalized to an electric field of $1 \mathrm{MV} / \mathrm{m}$. ature $(300 \mathrm{~K})$. Figure 2 shows the TSDC spectra of thirteen samples studied. The density current was normalized to an electric field of $1 \mathrm{MV} / \mathrm{m}$. A broad relaxation varying among the different samples in width, current maximum, and temperature position of the current maximum can be observed. Figure 3 presents the DSA results for the Cuevas de la Cabecera (La Blanquilla) sample. The result of the best fit to the experimental spectrum by the continuous line (Fig. 3(a)). Figure 3(b) presents the resulting energy histogram with the contributions of each Debye peak. From the histogram it is clear that there are several overlapping processes. The energy ranged from 0.1 to $0.8 \mathrm{eV}$. If a Gaussian profile is assumed for the energy distribution of each of them, at least four main different relaxations can be detected. Figure 3(c) represents the variation of $\tau_{0 i}$ associated with each elementary peak.

\section{Discussion}

According to the curves of Fig. 4 Ti-magnetite seems to be the chief magnetic mineral in most of these samples with Curie temperatures ranging from about 400 and $525^{\circ} \mathrm{C}$ (Cuevas de la Cabecera and Curricai) up to about $580^{\circ} \mathrm{C}$ (Domusky Norte and Los Mangles). In all these curves there is an initial rise of the magnetic susceptibility up to the main Curie drop. With the exception of Los Mangles (La Orchila), none of the heating curves are reversible upon cooling. This behavior is consistent with thermochemical alteration of Fe-bearing minerals.

Thermomagnetic curves also provide valuable information about the original firing conditions for these potsherds. Open fires used by Venezuelan Amerindian potters generally attained relatively low temperatures; between $600^{\circ}$ and $850^{\circ} \mathrm{C}$. In oxidizing firing conditions the free oxygen com-
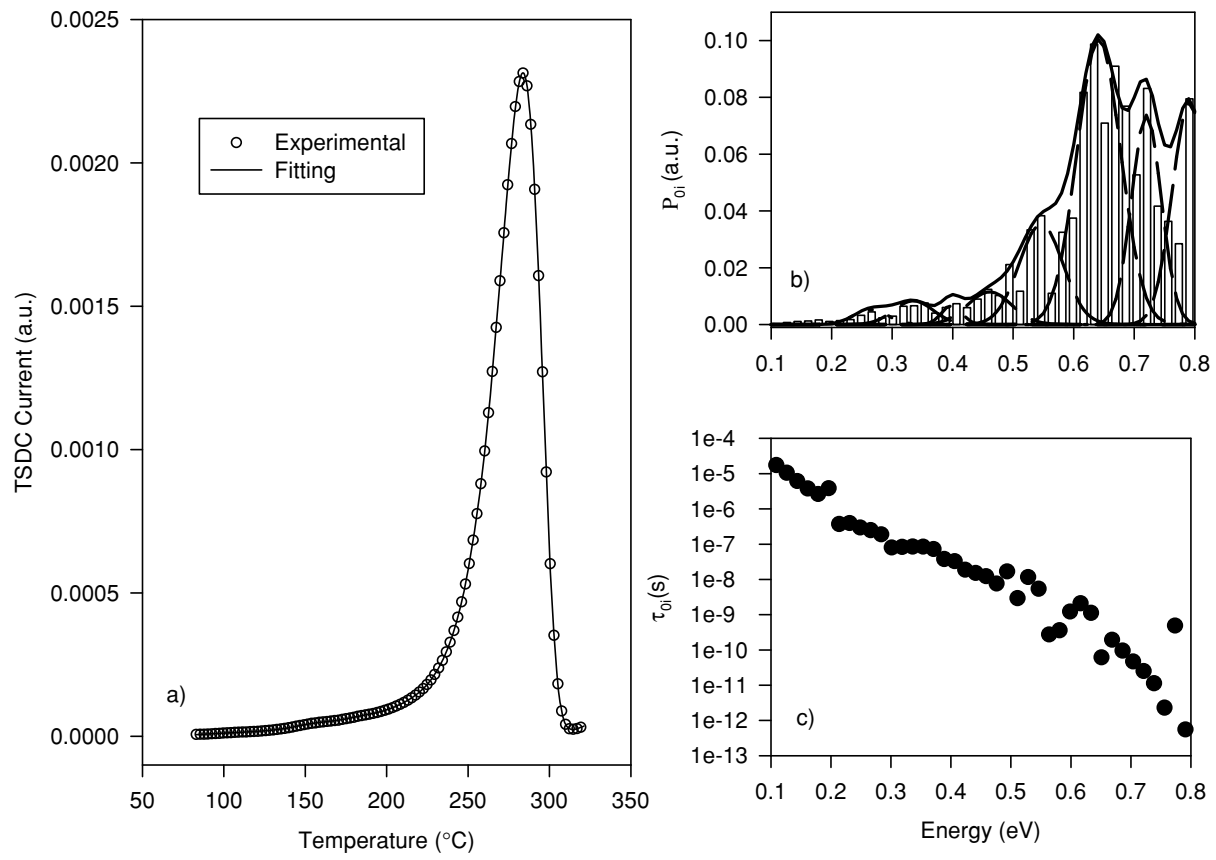

Fig. 3. DSA analysis of the relaxation spectrum for the Cuevas de la Cabecera (La Blanquilla) sample. a) Experimental and fitted curve; b) energy histogram of the contribution to the polarization of each elementary process. The broken lines are the Gaussian profiles that can be fitted into the histogram. The continuous line represents the sum of the broken line. c) Variation of the $\tau_{0 i}$ adjusted for each Debye process as a function of energy. 



Fig. 4. Normalized magnetic susceptibility curves measured in air for continuously increasing (and decreasing) temperatures. (a) Domusky Norte from Los Roques (ca. 1060 AD), (b) Cuevas de La Cabecera from La Blanquilla (ca. 1130 AD), (c) Los Mangles from La Orchila (ca. 1370 AD), and (d) Curricai from Las Aves (ca. $1530 \mathrm{AD}$ ).

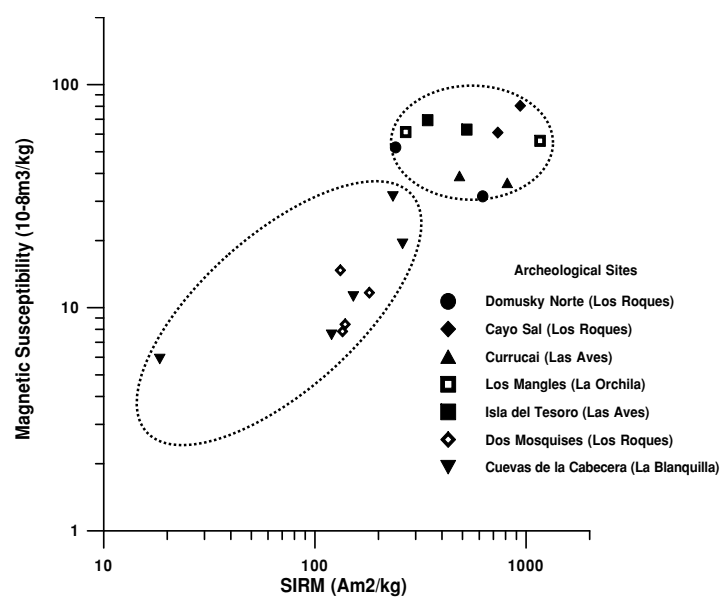

Fig. 5. Logarithmic scatter plot of site-average initial magnetic susceptibility versus SIRM (DC field $1 \mathrm{~T}$ ) for all the potsherds analyzed showing two major clusters of data.

bines with iron. A good draught provides enough oxygen to burn the fuel resulting in an atmosphere where carbonaceous matter in the paste will burn out. After complete removal of carbon, the iron oxides will achieve their maximum stages of oxidation. Such is the case of the sample from Los Mangles (Fig. 4(c)) where the ferrimagnetic phase appears to be dominantly oxidized to hematite or maghemite, as shown by the Curie temperature close to

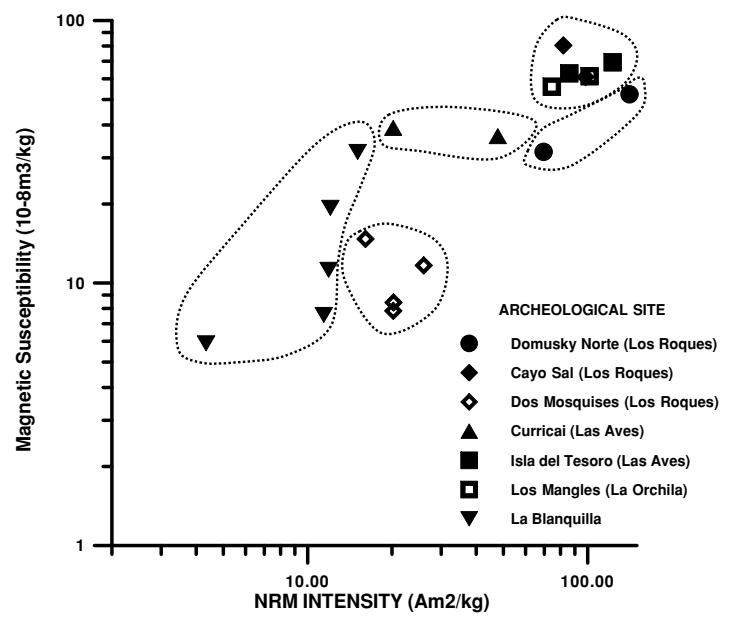

Fig. 6. Logarithmic scatter plot of site-average initial magnetic susceptibility versus site-averaged NRMs for all the potsherds analyzed showing five major clusters of data.

$600^{\circ} \mathrm{C}$. Moreover, the reversibility of the heating curve upon cooling reveals that the carbonaceous matter in this sample was completely burn during original firing of the sample. On the other hand, a reducing atmosphere is caused by a short supply of oxygen that prevents the entire combustion of the fuel. In addition, insufficient draught results in the accumulation of reducing gases (i.e. hydrogen, carbon, or carbon monoxide) so ceramics cannot obtain sources of 


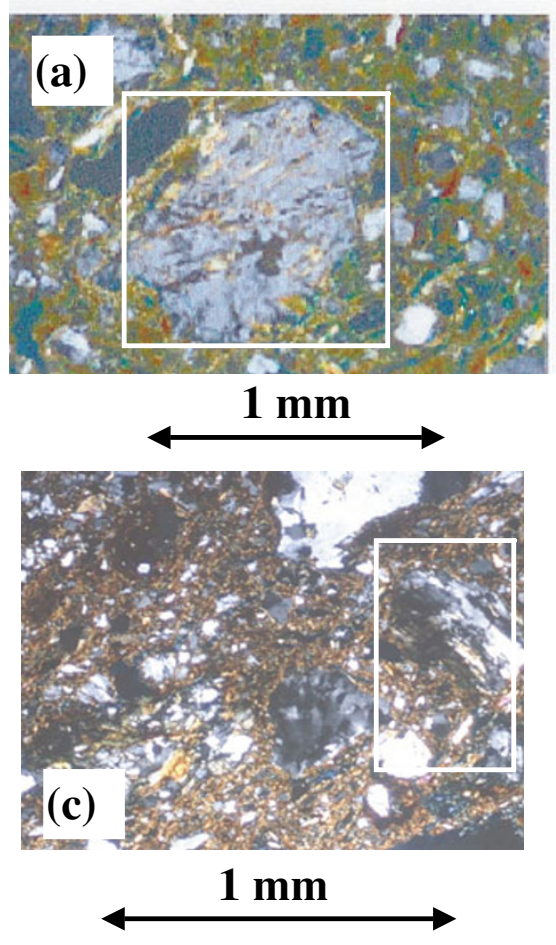

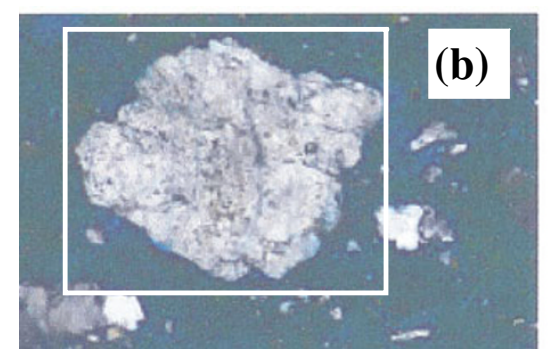

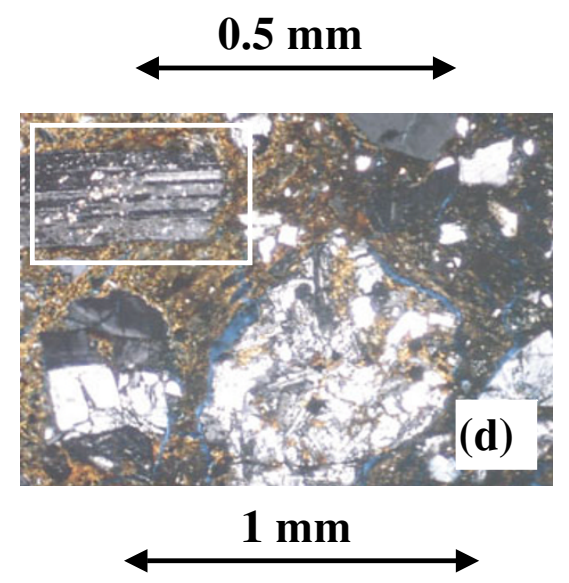

Fig. 7. Examples of transmitted XPL photomicrographs for potsherds from (a) Cuevas de la Cabecera (La Blanquilla) (b) Dos Mosquises (Los Roques), (c) Los Mangles (La Orchila) and (d) Curricai (Las Aves). Feldspars from Cuevas de la Cabecera (a) are less weathered than those from Dos Mosquises (b) as indicated in these examples by the feldspar crystals within the white frames. Samples from both Los Mangles (c) and Curricai (d) show poorly sorted mineral grains with angular edges also indicated in these examples by the mineral crystals within the white frames.

oxygen. That is perhaps the situation of Domusky Norte and Curricau (Figs. 4(a) and (d)) whose susceptibility values are much higher on cooling indicating the formation of new ferrimagnetic minerals such as magnetite. In these cases, organic materials in the paste remain partially unburned after original firing. Then, in a thermomagnetic experiment, throughout initial heating, iron oxides will reduce to a lower state.

Figure 5 shows a logarithmic scatter plot of initial magnetic susceptibility versus SIRM (DC field $1 \mathrm{~T}$ ). These magnetic parameters are first-order measures of the amount of ferrimagnetic material in the sample. However, the optimal separation between different site clusters results from comparing magnetic susceptibility with NRM values (Fig. 6). In the plot of Fig. 6 samples from Cuevas de la Cabecera (La Blanquilla) and Dos Mosquises (Los Roques) group into two different sets of data. This might be due to the fact that NRMs are not only sensitive to concentration of ferrimagnetic material, they also depend on grain size distributions, carriers of magnetic remanence and intensity of the geomagnetic field at the time the pottery was fired.

Although thin section analyses for samples from these two sites reveal similar compositions (i.e. quartz, feldspars etc.), the amount and state of preservation of the main mineral phases are completely different. For instance, feldspars from Cuevas de la Cabecera are less weathered than those from Dos Mosquises as shown in the photomicrographs of Figs. 7(a) and (b). The clays that form the matrix of these two samples have distinct compositions too. Clays from Cuevas de la Cabecera seem to have originated from a single source of fresh igneous/metamorphic rocks whereas those from Dos Mosquises show a mixture of both fresh and altered igneous sources that have suffered superficial weathering and/or transport. Moreover, despite the wide interval of initial magnetic susceptibility values, displayed by samples from La Blanquilla (Figs. 5 and 6), petrographic analyses of three different potsherds from this site reveal similar characteristics and a common source.

Samples from Los Mangles in La Orchila (AD 1370) and Cayo Sal in Los Roques (AD 1200) also share similar rock magnetic properties such as initial magnetic susceptibility and SIRMs (Fig. 5). Site-average NRMs are slightly different for these samples though (Fig. 6). Petrographic analyses of potsherds from Cayo Sal and Los Mangles reveal similar compositions and poorly sorted mineral grains with angular edges. They both contain high percentages of quartz (29 to $21 \%$ ), muscovite (12 to $5 \%$ ), fragments of metamorphic rocks $(7$ to $4 \%$ ) and traces of amphiboles and pyroxenes. This group of samples is characterized by the absence of feldspars $(<0.5 \%)$ and a rather high content of muscovite. The transmitted XPL photomicrograph in Fig. 7(c) corresponds to the sample from Los Mangles. This picture shows characteristic poorly sorted and angular fragments of metamorphic and igneous sources rich in quartz and mica.

Samples from Curricai and Isla del Tesoro, both from Las Aves (AD 1530) group in the same cluster of data of Fig. 5, but lie in two slightly different groups in the scatter plot of Fig. 6. Petrographic analyses of these samples reveal that they have common features, such as high percentage of volcanic fragments and feldspars. A transmitted XPL photomicrograph for the sample from Curricai (Fig. 7(d)) shows characteristic angular-shaped and poorly-sorted fragments 

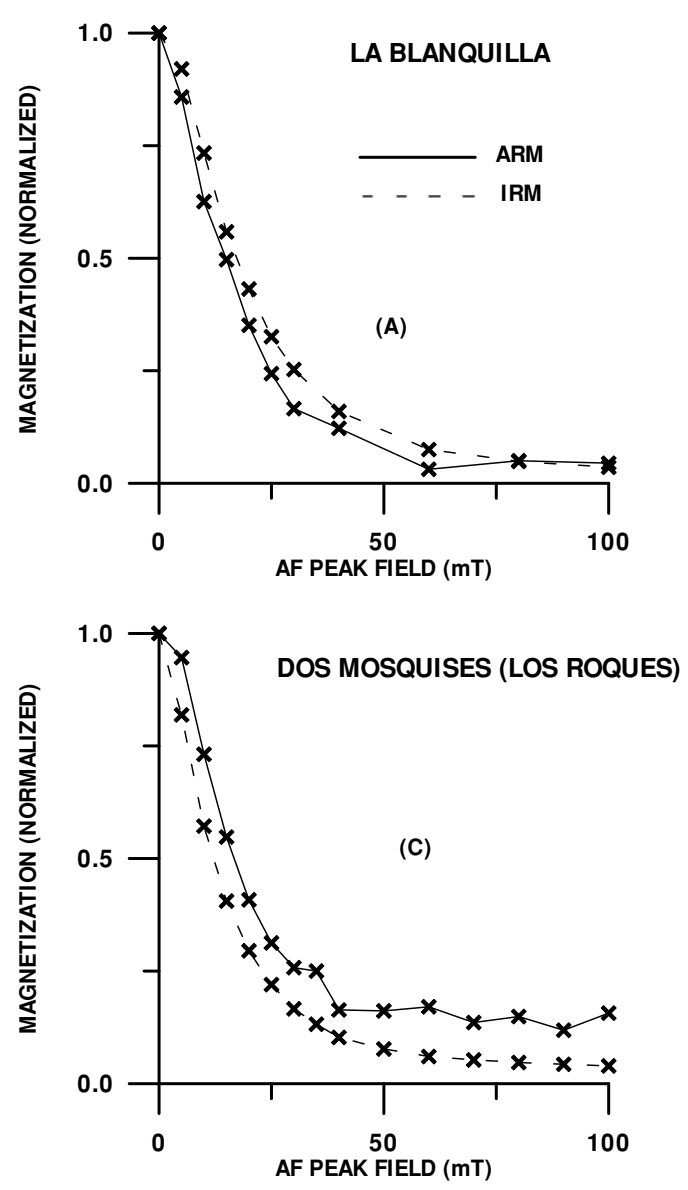
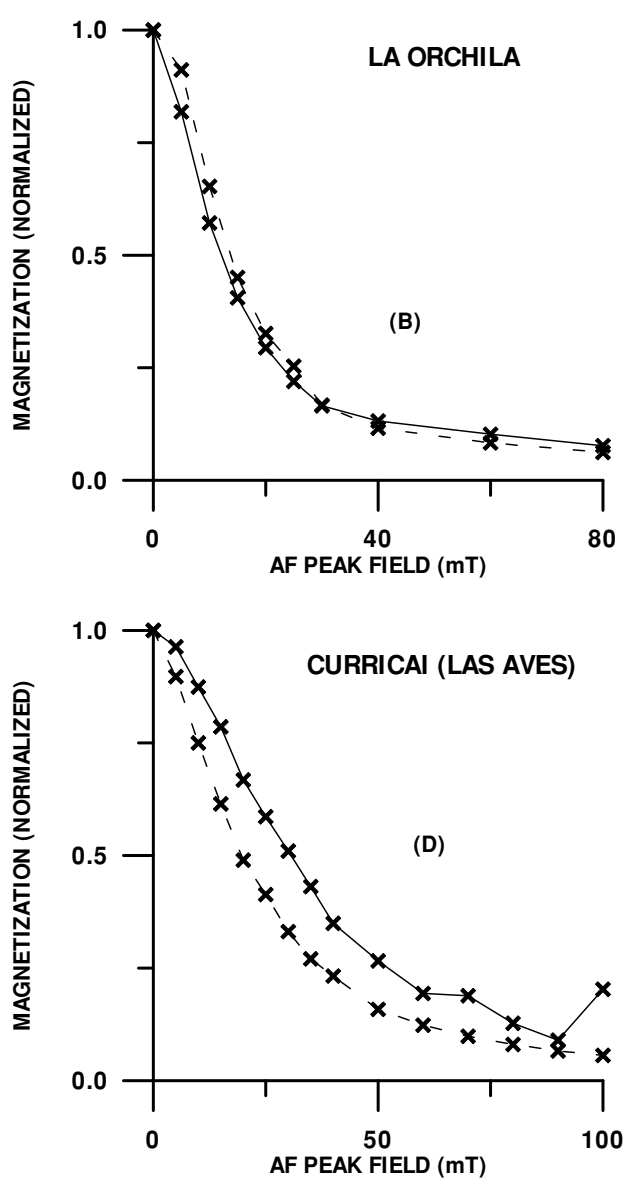

Fig. 8. Examples of a modified Lowrie-Fuller test applied to samples from (a) Cuevas de la Cabecera in La Blanquilla (ca. 1130 AD), (b) Los Mangles from La Orchila (ca. 1370 AD), (c) Dos Mosquises from Los Roques (ca. 1480 AD) and (c) Curricai from Las Aves (ca. 1530 AD). Continuous line is the normalized ARM AF demagnetization curve whereas dashed line represents the normalized IRM AF demagnetization curve.

of volcanic rocks, plagioclase and igneous and metamorphic quartz. Sizes of these grains range from clay $(\sim 70 \%)$ to fine silt $(\sim 30 \%)$. The color of the matrix varies from brownish red to yellowish red. The main minerals recognized in samples from Curricai and Isla del Tesoro are: feldspars, metamorphic quartz, fragments of volcanic rocks and abundant opaque minerals (i.e. hematite, magnetite and chromite).

Since petrographic analyses appear to agree with most of the clusters identified in the scatter plots of Figs. 5 and 6 , it is argued that initial magnetic susceptibility, SIRM and NRM are the magnetic parameters that better describe clay sources. In addition, magnetic grain size distributions were checked through a number of tests suited for such purposes (Figs. 8 through 10). A modified Lowrie-Fuller test (Johnson et al., 1975) was carried out in samples from Cuevas de la Cabecera in La Blanquilla (ca. 1130 AD), Los Mangles from La Orchila (ca 1370 AD), Dos Mosquises from Los Roques (ca. 1480 AD) and Curricai from Las Aves (ca. 1530 AD) (Fig. 8). In these experiments ARM was induced in an alternated peak field of $100 \mathrm{mT}$ with an added continuous field of $20 \mu \mathrm{T}$. SIRM was imparted with a DC field of $1 \mathrm{~T}$. Stability of these SIRM and ARM were then checked and compared upon AF stepwise demagnetizations. These tests are a valuable guide to determine the relative importance of single domain (SD) and multidomain (MD) grains in magnetite-bearing samples. According to Johnson et al. (1975) and Cisowski (1981), an ARM induced in a sample that contains mostly interacting SD magnetite, is more stable than the SIRM upon AF demagnetization. Consequently, the sample from Cuevas de la Cabecera (Fig. 8(a)) should have a dominant presence of MD magnetite. Los Mangles (Fig. 8(b)) shows an ambiguous overlap of the IRM and ARM demagnetization curves that could be due to either MD or SD magnetite. Finally, the test reveals the main occurrence of SD magnetite in the youngest samples from Dos Mosquises (Fig. 8(c)) and Curricai (Fig. 8(d)).

Effective domain-size also controls SIRM acquisition and its subsequent demagnetization response. This can be used to create crossover plots where \%SIRM is plotted as a function of the applied field (Fig. 9) The intersection points of the normalized IRM acquisition and demagnetization curves narrowly range between 0.2 and 0.3 suggesting the presence of interacting magnetite grains (Cisowski, 1981). The field of intersection varies from $15 \mathrm{mT}$ up to $40 \mathrm{mT}$ in sequential order from the oldest to the youngest sample.

The scatter plot of Fig. 10, including all the normalized IRM and AF peak field intersections against the outlined bounds of effective grain sizes for magnetite (Symons and Cioppa, 2000), shows no obvious definition of data clusters nor a clear trend or coincidence with the groupings de- 


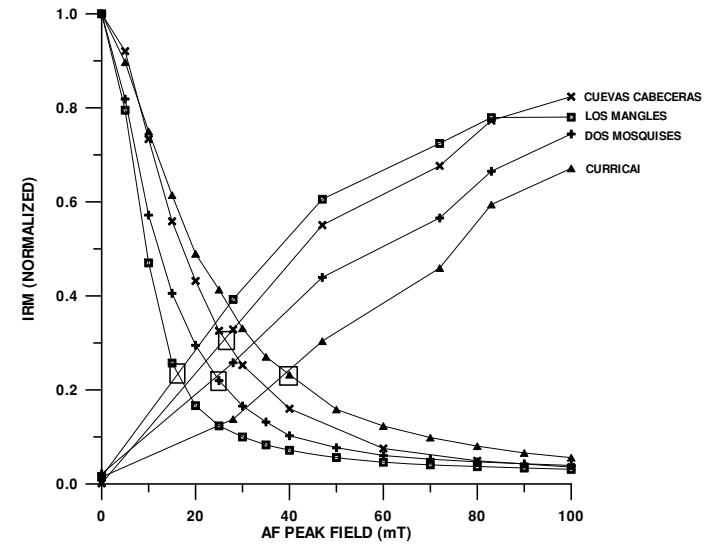

Fig. 9. Crossover plots where \%SIRM is plotted as a function of the applied field for samples from Cuevas de la Cabecera in La Blanquilla (ca. 1130 AD), Los Mangles from La Orchila (ca. 1370 AD), Dos Mosquises from Los Roques (ca. 1480 AD) and Curricai from Las Aves (ca. 1530 AD). The points of intersection of IRM acquisition and demagnetization are highlighted in a small square.

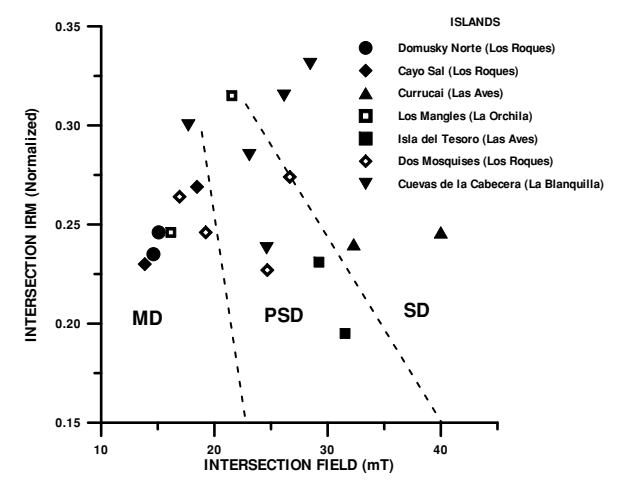

Fig. 10. Normalized IRM and AF peak field intersections of the 19 shards analyzed, plotted against the outlined bounds of effective grain sizes for magnetite defined by Symons and Cioppa (2000).

fined by Figs. 5 and 6 . It can be speculated that effective grain size distributions are not as much linked to the characteristics of the sourcing as to manufacturing techniques (i.e. preparation of the clay, finishing and firing). In fact, the original magnetic grain sizes, as well as other physical characteristics of the primary materials, must have changed considerably all through the process of craftsmanship.

Figure 11 compares rock magnetic (crossover SIRMs intersections from Fig. 10) with TSDC data (maximum current temperatures and activation energies). This scatter plot suggests the grouping of two major clusters of data that correlate the maximum current depolarization temperatures (as well as average activation energies) with SIRM intersection values. Suárez et al. (2003) have previously demonstrated, for a number of sedimentary rocks, that TSDC high temperature polarization spectra $(300 \mathrm{~K})$ are independent of chemical compositions. Instead, they seem to respond adequately to petrophysical characteristic of the material such as pore radius. In poorly consolidated rocks pore characteristics will depend on granulometric parameters such as mineral grain sizes, shape and sorting. Thus, it can be argued that the coarse correlations observed in Fig. 11, are mainly due to the fact that these dielectric and rock magnetic data are

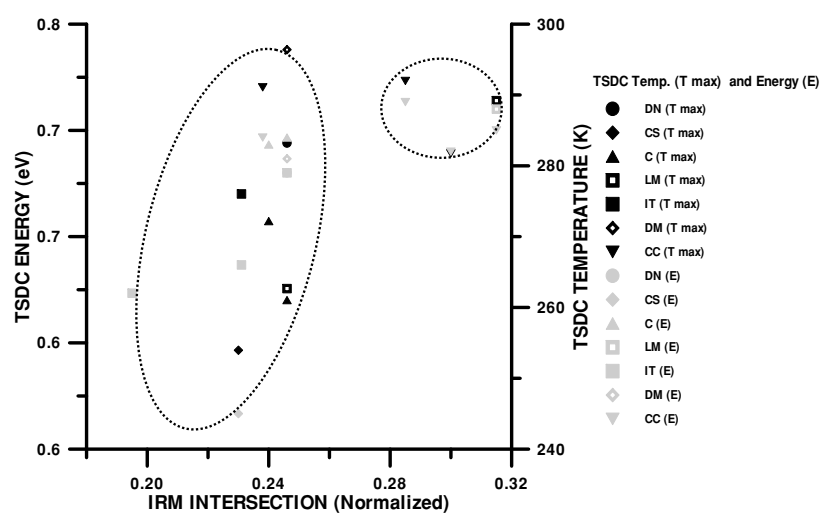

Fig. 11. Rock magnetic (crossover IRMs intersections from Fig. 10) plotted versus TSDC data (black symbols: maximum current depolarization temperatures and gray symbols: average activation energies) showing two major data trends. Island symbols stand as for the rest of the figures: DN: Domusky Norte in Los Roques, CS: Cayo Sal in Los Roques, C: Curricai in Ls Aves, LM: Los Mangles in La Orchila, IT: Isla Tesoro in Las Aves, DM; Dos Mosquises in Los Roques and CC: Cuevas de la Cabecera in La Blanquilla.

linked, in some extent, to pore-related features. It is reasonable to believe that such a level of correlation must change with firing though. In fact, beginning at temperatures of about $350^{\circ} \mathrm{C}$, the edges of the clay particles use to soften and adhere to one another (sintering). Finally, above $900^{\circ} \mathrm{C}$ they fuse together as glass (vitrification). Since sintering does not necessarily affect magnetic minerals in the same way it affects clays; as far as firing temperatures approach to vitrification levels, a lesser amount of correlation between dielectric and rock magnetic data would be expected. Yet, in most cases, Venezuelan Amerindian pottery samples are relatively porous (non vitreous) wares, in which clay particles have only suffered partial fusion of their edges due to incipient heating at peak temperatures no higher than $850^{\circ} \mathrm{C}$.

\section{Conclusions}

From this first attempt to characterize archeological ceramics (i.e. 19 potsherds from different Prehistoric Amerindian sites in 7 Venezuelan islands), using a combined magneto/dielectric approach, the following conclusions can be drawn:

Magnetic parameters that best describe clay sources might be initial magnetic susceptibility, SIRM and NRM. Effective magnetic grain size distributions are related less to the characteristics of the clay sources than to the manufacturing techniques (i.e. preparation of the clay, finishing and firing).

Thermomagnetic curves might provide valuable information about the original firing conditions of the potsherds.

Crossover SIRM intersections seem to correlate in a complex way with TSDC data (maximum current temperatures and activation energies). This might be due to the fact that these dielectric and rock magnetic parameters are somehow both linked to porerelated features. However such a level of correlation should be more or less clear cut, depending on the maximum firing temperatures achieved by the original potters. 
Further analyses on a larger number of archaeological samples, including some from mainland Venezuela, are still pending.

Acknowledgments. We are grateful to Marlena and Andrzej Antczack (Universidad Simon Bolivar, Caracas) who generously supplied the pottery samples. We are also very much in debt with David Dunlop (University of Toronto, Canada), Carolina Ayala and Germán Bayona (Corporación Geológica ARES, Colombia) and Wyn Williams (Edinburgh University, UK). Thoughtful reviews by Don Tarling and an anonymous referee greatly improved the paper. This research was partially funded by a PPI working fund to V. Costanzo-Alvarez and M. Aldana (Decanato de Investigación y Desarrollo, Universidad Simón Bolívar). N. Suárez and M. C. Hernández gratefully acknowledge partial support by FONACIT (Project G-2005000449).

\section{References}

Aldana, M., E. Laredo, A. Bello, and N. Suárez, Direct signal analysis applied to the determination of the relaxation parameters from TSDC spectra of polymers, J. Polymers. Sci. B, 2197-2206, 1994.

Bishop, R. L., Archeometry of pre-Columbian sites and artifacts, Proceedings of the Symposium organized by UCLA, Institute of Archeology and the Getty Conservation Institute, Los Angeles, California, 15-63, 1992.

Bishop, R. L. and M. J. Blackman, Instrumental neutron activation analysis of archeological ceramics: scale and interpretation, Accounts of Chemical Research, 35(8), 603-610, 2002.

Boutonnet-Fagegaltier, N., J. Menegotto, A. Lamure, H. Duplaa, A. Caron, C. Lacabanne, and M. Bauer, Molecular mobility study of amorphous and crystalline phases of a pharmaceutical product by thermally stimulated current spectroscopy, J. Pharmaceutical Sci., 91(6), 1548-1560, 2002.

Brandt, M. C. and V. Costanzo-Alvarez, A preliminary Archeomagnetic study of prehistoric Amerindian pottery from Venezuela, Interciencia, 24(5), 293-299, 1999.

Bucci, C. and R. Fieschi, Ionic thermoconductivity. Method for the investigation of polarization in insulators, Physics Rev. Lett., 12, 16-19, 1964.

Cisowski, S., Interacting versus Non-interacting single domain behavior in natural and synthetic samples, Physics of the Earth and Planetary Interiors, 26, 56-62, 1981.

Costanzo-Alvarez, V., M. Aldana, N. Suárez, J. L. Gago, and W. Williams, Rock Magnetic and Dielectric characterizations of a formational contact in Cretaceous strata (Eastern Venezuela), Physics and Chemistry of the Earth, 24(9), 763-771, 1999.

Costanzo-Alvarez, V., W. Williams, A. Pilloud, O. Mirón Valdespino, and M. Aldana, Paleomagnetic results of remagnetized mid-cretaceous (Albian-Cenomanian) strata of northeastern Venezuela, Geophys. J. International, 41, 337-350, 2000.

Johnson, H. P., W. Lowrie, and D. V. Kent, Stability of anystheretic remanent magnetization in fine and coarse magnetite and maghemite particles, Geophys. J. Roy. Astro. Soc., 41, 1-10, 1975.

Kasztovszky, Zs., M. M. Mackowiak-Antczak, A. Antczak, B. Millan, J. Bermudez, and L. Sajo-Bohus, Provenance study of Amerindian pottery figurines with Prompt Gamma Activation Analysis, Nucleonik, 49(3), 107-113, 2004.

McDougall, J. M., D. H. Tarling, and S. E. Warren, The magnetic sourcing of obsidian samples from Mediterranean and Near Eastern Sources, $J$. Archeological Science, 10, 441-452, 1983.

Neff, H., J. W. Cogswell, and L. M. Ross, Jr., Supplementing bulk chemistry in archeological ceramic provenance investigations, in Patterns and Process: A Festchrift in Honor of Dr. Edward V. Sayre, edited by L. Van Zelst, 201-224, Washingtong DC Smithsonian Center for Materials Research and Education, 2003.

Sajo-Bohus, L., M. M. Mackowiak-Antczak, E. D. Greaves, A. Antczak, J. Bermudez, Zs. Kasztovszky, T. Poirier, and A. Simonits, Incipient Archeometry in Venezuela, Provenance study of pre-Hispanic pottery figurines, J. Radioanalytical and Nuclear Chemistry, 265(2), 247-256, 2005.

Suárez, N., E. Laredo, A. Bello, and J. Kohn, Molecular relaxation mechanisms of tyrosine-derived polycarbonates by thermally stimulated depolarization currents, J. Apply. Polim. Sci., 36(11), 1457-1466, 1997.

Suárez, N., S. Brocchini, and J. Kohn, The study of water uptake in degradable polymers by thermally stimulated depolarization currents, Biomaterials, 19, 2347-2356, 1998.

Suárez, N., M. Aldana, V. Costanzo-Alvarez, and J. Mendoza, Dynamical properties of water relaxations at a gradational lithological contact between different types of porous sedimentary rocks, J. Non-Crystalline Solids, 328, 20-30, 2003.

Symons, D. T. A. and M. T. Cioppa, Crossover plots: a useful method for plotting SIRM data in paleomagnetism, Geophys. Res. Lett., 27(12), 1779-1782, 2000.

Urrutia-Fucugauchi, J., Preliminary results of a rock-magnetic study of obsidians from central Mexico, Geofisica Internacional, 38, 83-94, 1999.

Vasquez, C. A., H. G. Nami, and A. E. Rapalini, Magnetic sourcing of obsidians in Southern South America: some successes and doubts, $J$. Archeological Science, 28, 613-618, 2001.

Vaz, J. E. and J. M. Cruxent, Determination of the provenience of majolica pottery found in the Caribbean area using its gamma ray induced thermoluminiscence, American Antiquity, 40(1), 71-81, 1975.

V. Costanzo-Alvarez (e-mail: vin61158@yahoo.com), N. Suárez, M. Aldana, M. C. Hernández, and C. Campos 